\title{
FRANCISCO GINER, ESTUDIANTE DE BACHILLERATO EN EL INSTITUTO JORGE JUAN DE ALICANTE (UNA NOTA DOCUMENTAL)
}

\author{
RAQUEL LÓPEZ SÁNCHEZ \\ Universidad Autónoma de Madrid
}

\section{Resumen}

El presente estudio aborda la etapa formativa de Francisco Giner de los Ríos en el Instituto Jorge Juan de Alicante, durante el periodo comprendido entre 1848 y 1852. Para ello, tomamos como punto de partida el expediente académico del entonces alumno Francisco Giner, dirigiendo una mirada retrospectiva hacia su trayectoria escolar en la capital alicantina, y proyectándola hacia la profunda reforma de la sociedad que abordó el polifacético docente mediante la metamorfosis del sistema educativo estatal.

Palabras clave: Francisco Giner de los Ríos; Instituto Jorge Juan de Alicante; expediente académico.

\begin{abstract}
The following study approaches the formative stage of Francisco Giner de los Ríos in the Secondary School Jorge Juan of Alicante, during the period understood between 1848 and 1852. We take as a point of departure the academic record of Francisco Giner as a pupil, directing a retrospective look at his academic history in the capital of Alicante, and projecting it towards the deep reform of the society that the versatile teacher approached by means of the metamorphosis of the State's educational system.
\end{abstract}

Keywords: Francisco Giner de los Ríos; Secondary School Jorge Juan of Alicante; academic record. 
—Sí, Augusto, sí — prosiguió don Avito-; la vida es la única maestra de la vida; no hay pedagogía que valga. Solo se aprende a vivir viviendo, y cada hombre tiene que recomenzar el aprendizaje de la vida de nuevo...

Niebla, Miguel de UnAmuno

Adentrarse en la irrepetible figura de Francisco Giner de los Ríos es convocar el reconocimiento del pedagogo que «estimulaba el alma de sus discípulos - de los hombres o de los niños- para que la ciencia fuese pensada, vivida por ellos mismos» (Machado, 1994: 295). El vitalismo regeneracionista de las palabras de Antonio Machado hacia el que fuera su maestro en la Institución Libre de Enseñanza dibuja con nitidez el talante comprometido de don Francisco con la dignificación del pensamiento y del trabajo en muy variados ámbitos del saber humano. La plenitud de sus enseñanzas y el esmero vocacional que calcifican en la esperanza krausista frente a la anemia intelectual de la vida española perfilan el proyecto de Giner hasta copar la formación de un «hombre dueño de sí mismo, capaz de trabajar y valerse por sí; un núcleo de fuerzas espirituales con iniciativa individual, una persona libre» (Giner de los Ríos, 1990: 134-135).

A pesar de la amplísima cantera de disciplinas sobre las que teorizó don Francisco Giner, uno de los vacíos documentales que acusan la trayectoria del enseñante es precisamente el que resulta del envés de su espíritu «laborioso y activo» en el ámbito de la docencia (Machado, 1994: 296): su faceta como alumno. Sabemos mucho de su función como enseñante; sin embargo, la juventud —-mejor aún, la etapa formativa del Francisco Giner niño- es un territorio en alguna medida por recorrer.

Un acercamiento apresurado a su biografía nos sitúa de inmediato en su Ronda natal, en la provincia de Málaga. Don Francisco nace allí en 1839 en el seno de una familia acomodada. A la temprana edad de nueve años su padre, el empleado de Hacienda Francisco Giner de la Fuente, fue destinado a Alicante, donde la familia se estableció en el número 25 de la Plaza Juan de Dios. A partir de este momento, los esbozos biográficos y los empréstitos de las investigaciones que calibran los avatares de su carrera académica nos tienen acostumbrados a pasar de soslayo por el interesante - y esto es así por lo inédito- capítulo de la etapa de formación del niño Francisco Giner una vez hubo ingresado en el Instituto Provincial de 2. ${ }^{a}$ Enseñanza de Alicante, el actual Instituto de Educación Secundaria Jorge Juan (que, en el momento en que redacto estas líneas, dirige el profesor de Latín y Griego D. José Miguel Baeza Bueno). El expediente académico del que firmaba por entonces como Francisco Giner y Ríos, cedido por el 
Instituto, permite que una mirada retrospectiva por este conjunto documental delinee con alguna precisión la memoria de don Francisco Giner en tierras de Alicante.

Previamente, y en solidaridad con esta tarea de descortezar la estadía educativa de don Francisco Giner en Alicante, la ocasión es propicia para ubicar en los anaqueles de la historia una realidad urbana que, a menudo, escapa a quienes transitamos por las calles de nuestras ciudades. Reconociendo así el mapa arquitectónico de la provincia, el Instituto de Segunda Enseñanza en que cursó don Francisco Giner se situaba en el número 9 de la calle Villavieja, frente a las recias estructuras de la Iglesia - hoy día Basílica - de Santa María en la plaza homónima. La Asegurada $^{1}$, como se conocía al caserón que el Ayuntamiento, concretamente el arquitecto Emilio Jover, había acondicionado en 1843 para albergar una escuela, constituye la construcción civil más antigua de Alicante (Cerdán Tato, 1993). Edificada en las postrimerías del siglo XVII «con la finalidad de almacenar grano y harinas para afrontar hambrunas» (Valdés, 2010)², es en 1845 cuando su sobria armazón se reviste de pupitres y encerados para acoger a un total de noventa alumnos matriculados durante el primer año académico. Suerte de epifanía o, tal vez, necesidad de escamotear los cedazos del tiempo y del olvido, no resulta difícil imaginar a un presuroso don Francisco Giner atravesar la Plaza de Santa María para recibir sus lecciones.

Así las cosas, el repertorio de documentos que conforman el expediente da cumplida cuenta de su instrucción en el centro durante el periodo comprendido entre 1848 y 1852, fecha esta última en la que culmina sus estudios con la obtención del grado de Bachiller en Filosofía, de

1. Viravens y Pastor (1876: 249) escribe: «El frontispicio principal se hizo de piedra de la cantera de San Julián: en él había ocho ventanas con rejas, en cuyo intermedio superior se puso en el centro el escudo de Armas de esta Ciudad, grabado en piedra [...]. La puerta de la Asegurada forma un arco, que exorna una sencilla portada con pedestales y pilastras; y sobre el cornisón que sostienen se colocó una lápida con los nombres del Justicia, Jurados, Racionero y Escribano-Secretario, que estaban al frente del Municipio en el año 1685 en que se hizo la referida casa».

2. Cfr. Jaén i Urban (1999: 33): «Fue levantada por el municipio para uso público, por lo que aparece el escudo de Alicante en la fachada. A lo largo de su historia ha sido utilizado para usos diversos tales como archivo municipal, escuelas, instituto y escuela de comercio hasta 1955. [...] Las plantas son diáfanas, disponiendo los entramados de los pisos en tres crujías paralelas a fachada que descansan en amplios arcos de medio punto y pilastras, todo de sillería, sin ornamentación, creando un espacio donde el valor arquitectónico se basa en la calidad constructiva». 


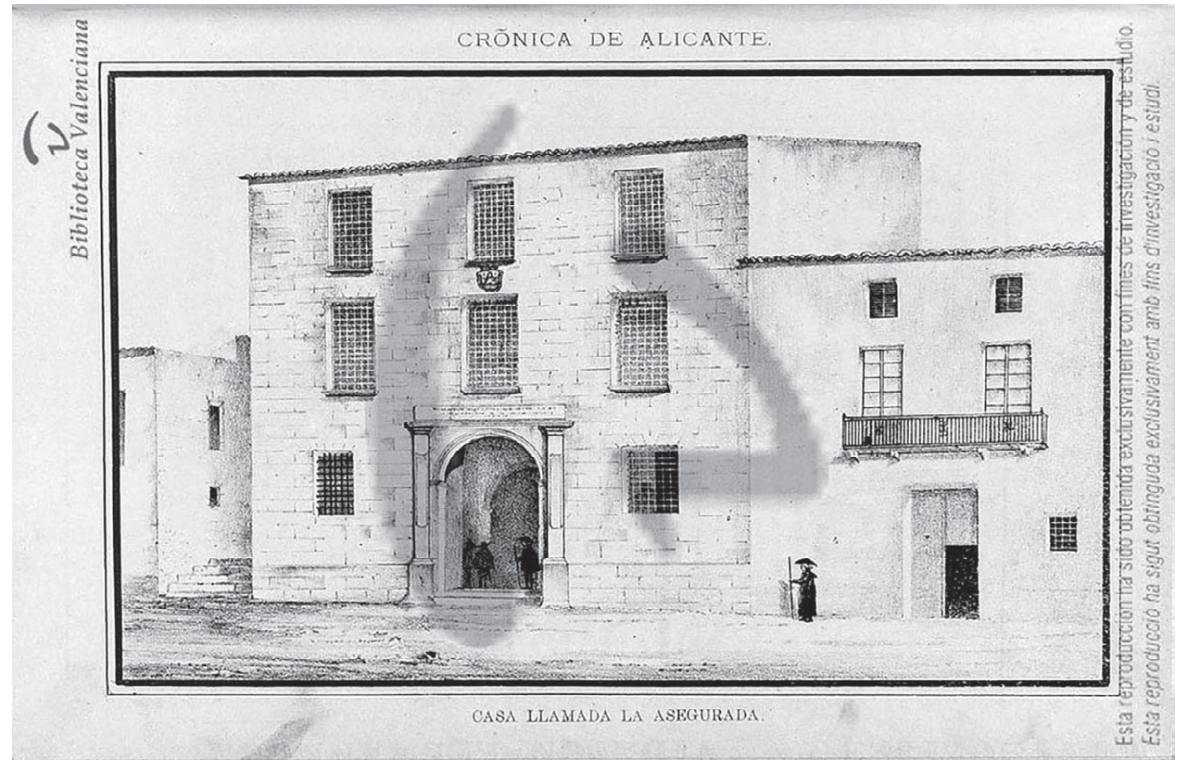

Imagen 1. La Asegurada, en la Crónica de Rafael Viravens y Pastor (1876).

conformidad con el Plan de Instrucción Pública promulgado por Pedro José Pidal y Antonio Gil de Zárate en 1845.

Apenas emprendido el viaje hacia Levante, el 30 de octubre de 1848 Francisco Giner remitió al director del Instituto una instancia solicitando su incorporación al centro, que durante esos años dirigía D. Agustín González, así como traslado de expediente desde el Colegio de Santo Tomás de Aquino en la ciudad de Cádiz — incorporado a la Universidad de Sevilla_-, en el que había cursado su primer año de Segunda Enseñanza Elemental y había comenzado también el segundo curso escolar. La instancia iba acompañada de un certificado que nueve días antes había redactado en Cádiz don Vicente Gómez de Bustamante, profesor secretario del colegio gaditano, que acreditaba la matrícula del estudiante en el centro y encarecía las notorias facultades del joven solicitante. El texto reza así:

Don Vicente Gómez de Bustamante Académico de Honor y Catedrático de Matemáticas de la Academia Nacional Gaditana de las Nobles Artes y de la Escuela especial de dicha ciencia en el Consulado de esta Plaza [...] Profesor Secretario del Colegio de 2. ${ }^{a}$ Enseñanza de $1 .^{a}$ Clase de Santo Tomás de Aquino de esta Ciudad e individuo de varias corporaciones literarias. 


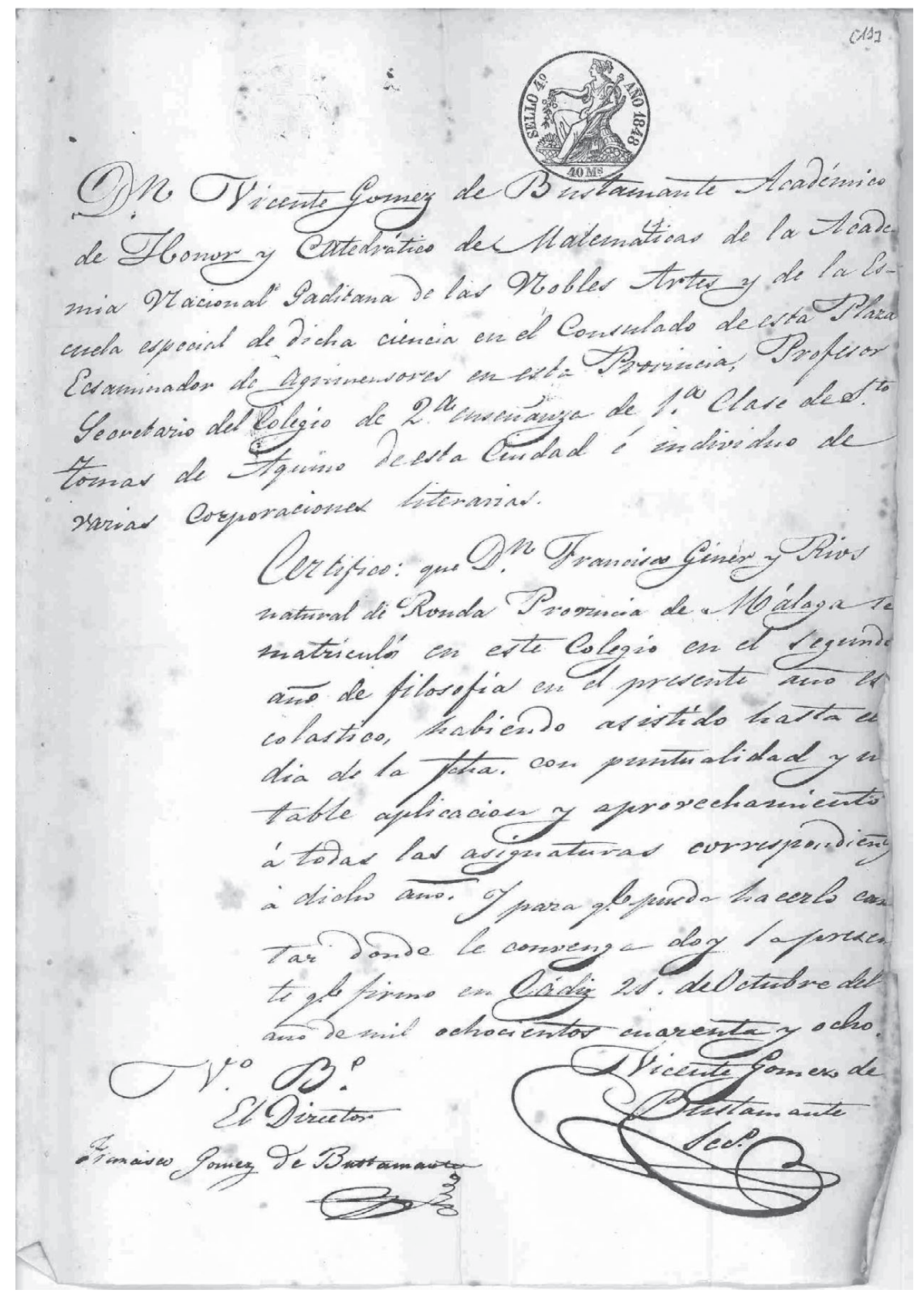

Imagen 2. Original del certificado redactado por Don Vicente Gómez de Bustamante. 
Certifico: que Don Francisco Giner y Ríos, natural de Ronda provincia de Málaga se matriculó en este Colegio en el segundo año de Filosofía en el presente año escolástico, habiendo asistido hasta el día de la fecha con puntualidad y notable aplicación y aprovechamiento a todas las asignaturas correspondientes a dicho año...

Con el visto bueno del director, otro miembro de la familia Gómez de Bustamante, don Francisco en esta ocasión, y con la anuencia del Secretario General de la Universidad de Sevilla, la petición de Francisco Giner se admitía a trámite, y el muchacho quedó matriculado en el centro alicantino el 13 de noviembre de 1848.

El primer año del recién llegado discente, Giner obtiene la calificación de sobresaliente en su segundo curso de Filosofía elemental, con lo que se dirige al director del Instituto solicitando autorización, conforme al reglamento, para poder optar al premio ordinario de excelencia académica. La instancia, registrada con fecha de 2 de julio de 1849, jalona un hito en el compendio documental de su expediente; se trata de la primera vez que, excepcionalmente, aparece rubricado «Francisco Giner de los Ríos».

Atestiguado así en la declaración del director, la petición de don Francisco Giner se resolvió favorablemente, aunque no puede decirse lo mismo del fallo del tribunal de catedráticos que ponderaban los ejercicios de Giner y de otro candidato al mismo premio, el finalmente galardonado don Estanislao Julián y Pérez.

Transcribimos a continuación un extracto del secretario en la sala de actas públicas de lo que a todas luces constituyó una contrariedad para Giner, habida cuenta de las aptitudes mostradas en sus ejercicios literarios, muy probablemente relacionados con la traducción y composición de textos en lengua castellana y latina, según se desprende de algunos originales que se recogen en el expediente:

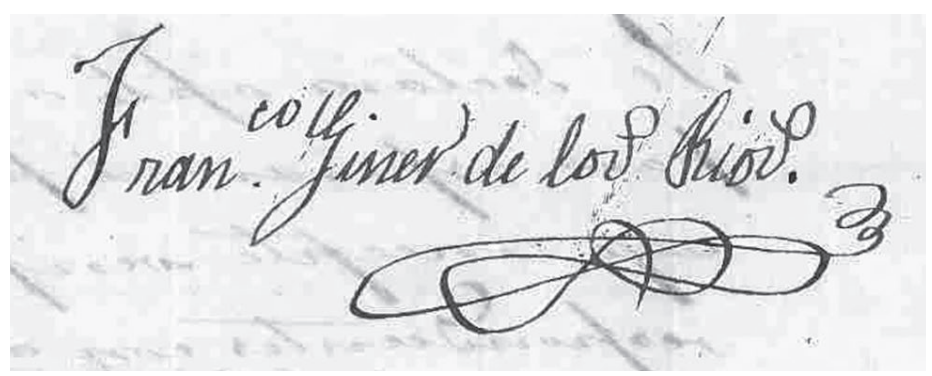

Imagen 3. Rúbrica original de don Francisco Giner de los Ríos. 


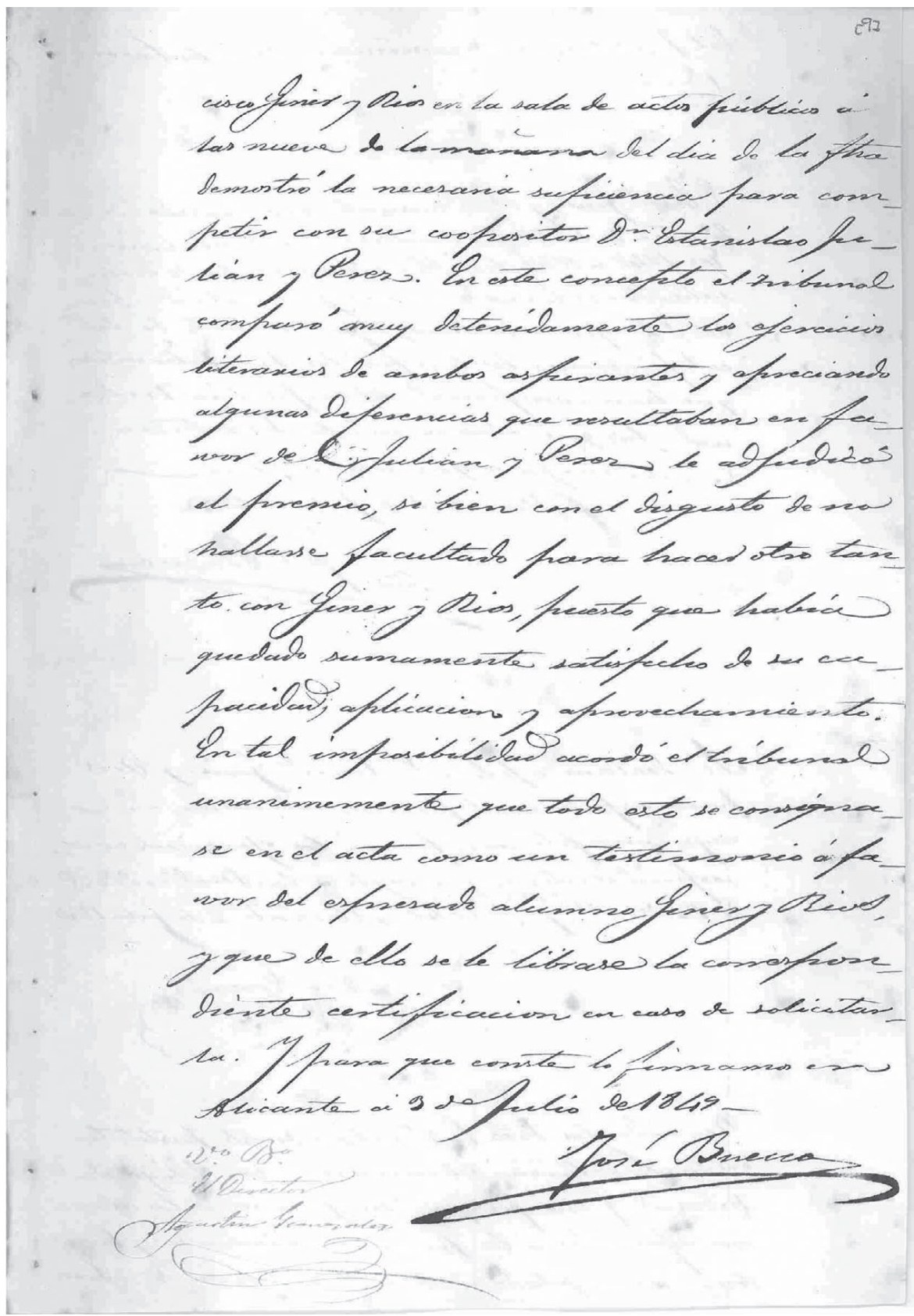

Imagen 4. Acta del secretario a propósito de la evaluación de los ejercicios optantes al premio ordinario. 
... En este concepto el tribunal comparó muy detenidamente los ejercicios literarios de ambos aspirantes y apreciando algunas diferencias que resultaban en favor de Julián y Pérez le adjudica el premio, si bien con el disgusto de no hallarse facultado para hacer otro tanto con Giner y Ríos, puesto que habrá quedado sumamente satisfecho de su capacidad, aplicación y aprovechamiento. En tal imposibilidad acordó el tribunal unánimemente que todo esto se consignase en el acta como un testimonio a favor del expresado alumno Giner y Ríos, y que de ello se le librase la correspondiente certificación en caso de solicitarla.

Posteriormente, el expediente adiciona un volumen de actas correspondientes a los cursos académicos 1849-1850, 1850-1851 y 1851-1852, que atañen al tercer, cuarto y quinto año de Filosofía elemental. En efecto, la relación de asignaturas, número de lecciones y calificaciones conforman un mosaico que concita dos circunstancias: la primera, la constancia y aprovechamiento de Francisco Giner en sus estudios durante los cuatro años que permaneció inscrito en el Instituto de la capital alicantina; la segunda, el testimonio del plan de estudios aprobado tres años antes de que el entonces niño Giner se trasladase con su familia a Alicante.

A esta luz, y como se ha dicho ya, los estudios de don Francisco Giner arraigan en las estructuras del Plan Pidal, sancionado nuevamente en 1857 por la archiconocida Ley Moyano, y con la que no transigiría la labor educacional de nuestro teórico y filósofo. De conformidad con la disposición firmada por el Ministerio de Gobernación a expensas del crédito concedido por Isabel II, el artículo 57 de la legislación refrendaba la fundación de un Instituto en cada capital de provincia, lo que sin duda vino a suponer la paulatina gravitación de la vida española hacia la cultura y la ciencia (Ruiz Berrio, 2008). El Instituto Jorge Juan de Alicante en que don Francisco Giner cursó el Bachillerato se convertía así, tras su inauguración en 1845 en la Asegurada, en el establecimiento que posibilitaba el acceso a la Enseñanza Media en la provincia.

Ahora bien, pese a la aparente panacea que suponía el nuevo plan de estudios decretado, la concepción de la paideia en que se formó don Francisco Giner se aparta mucho del principio epistemológico de texto vivo - como se consideró a los pedagogos deudatarios del krausismo- para encallar en el radicalismo eclesiástico rampante en la Década moderada (Álvarez Lázaro, 2005: 136; Ríos Urruti, 1949). En estos términos, y si cabe afirmarlo así, cláusulas como la que enseguida apuntamos constituyen ex aequo el germen de la decrepitud de un sistema educativo y de la modernidad pedagógica de los futuros prohombres de la ILE: «si se 


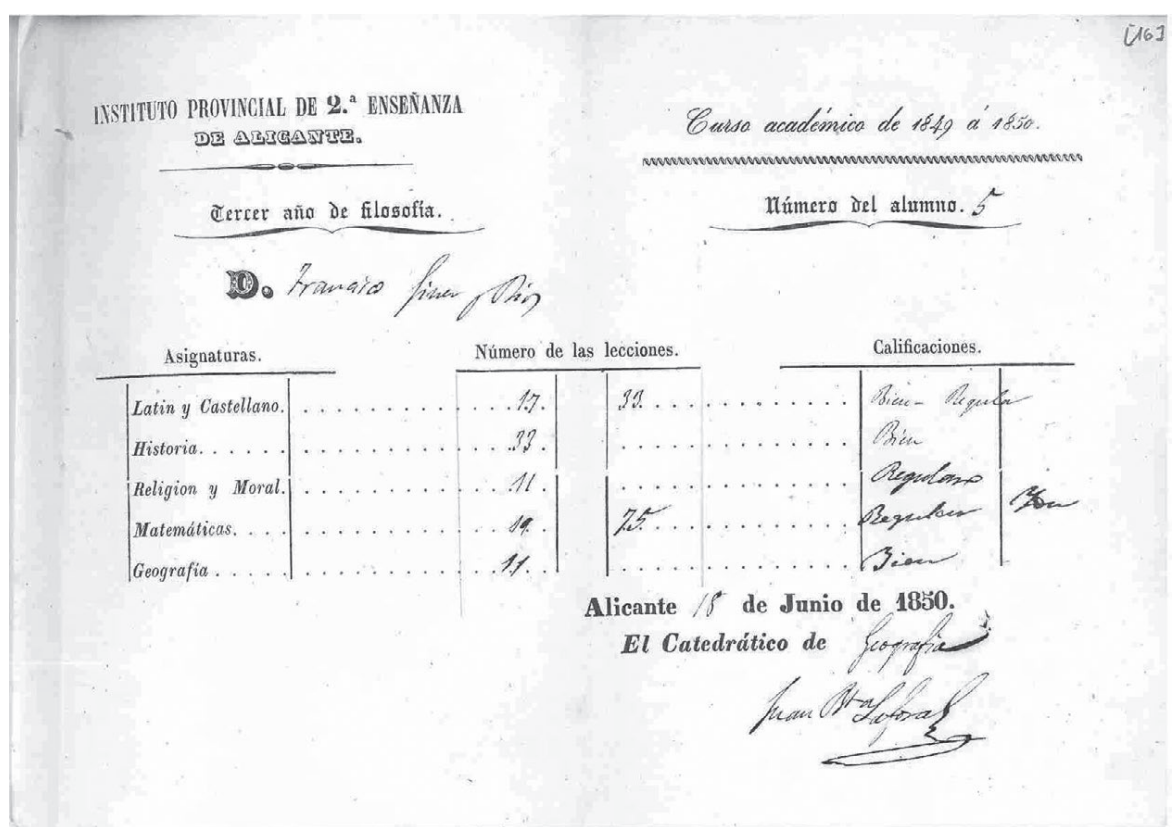

Imagen 5. Calificaciones de Francisco Giner en el curso académico de 1849 a 1850.

atiende a lo que exige una educación perfecta [...] sin la religión, sin que se labren desde la niñez sus sanas doctrinas en el corazón del hombre, perdidos serán cuantos esfuerzos se hagan para cultivar su entendimiento» (Real Decreto aprobando el Plan General de Estudios, de 17 de septiembre de 1845). Si estos planteamientos parecen circunstanciales, la etapa formativa de don Francisco Giner en Alicante evidencia el florecimiento de la enseñanza de carácter confesional, tal y como constata la materia de «Religión y Moral» diseminada en el decurso de sus estudios en el «Jorge Juan»; una asignatura esta, por cierto, que se resuelve mayoritariamente con la calificación de «regular».

Estos rasgos del Plan Pidal se subrayarían con la aprobación de la citada Ley Moyano en 1857, en un momento en que don Francisco Giner comenzaba a curtirse en su carrera académica y a imbuirse de las doctrinas krausistas a través de Nicolás Salmerón, Julián Sanz del Río y Fernando de Castro - a quienes conocería al filo de la década de los sesenta-. La Ley Moyano sería enjuiciada duramente años más tarde por don Francisco Giner en sus Escritos sobre la Universidad Española (1893-1904), cuyas 


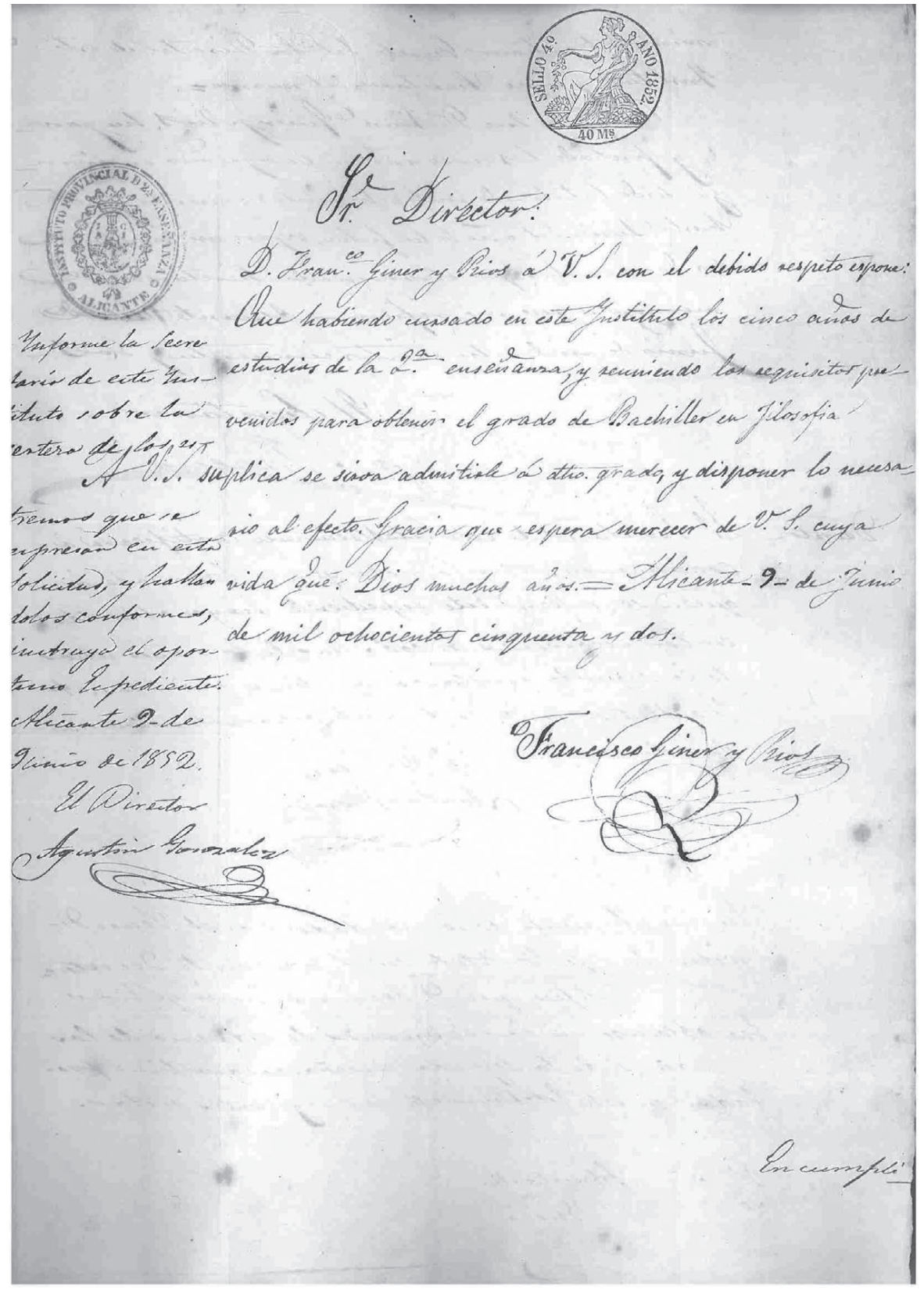

Imagen 6. Solicitud de Francisco Giner del grado de Bachiller en Filosofía en 1852. 
bases intelectuales ponían de manifiesto la confirmación de la nueva praxis pedagógica.

Al cabo, el expediente de Francisco Giner se cierra con las certificaciones correspondientes al logro del grado de Bachiller en Filosofía. Este apartado enlaza con una nueva instancia al director del centro, fechada el 9 de junio de 1852 y en la que razona lo que sigue:

D. Francisco Giner y Ríos a V. S. con el debido respeto expone: que habiendo cursado en este Instituto los cinco años de estudios de la 2. ${ }^{\mathrm{a}}$ enseñanza, y reuniendo los requisitos prevenidos para obtener el grado de Bachiller en Filosofía, a V. S. suplica se sirva admitirle a otro grado, y disponer lo necesario al efecto. Gracia que espera merecer de V. S. cuya vida de Dios muchos años.

Entendemos efectivamente que, cuando don Francisco Giner alude a sus «cinco años de estudios» en el Instituto alicantino, se está refiriendo a la culminación de la Segunda Enseñanza, que había comenzado, como ya se ha señalado, en la provincia de Cádiz. Estaba así en disposición de acceder a los estudios de Facultad mayor, para lo que marcharía sucesivamente a las Universidades de Barcelona — ciudad en que se forma en Jurisprudencia-, Granada — donde obtiene la licenciatura en Derecho-y la Central madrileña —en que recaló para realizar sus estudios de Doctorado en Filosofía del Derecho y Derecho Internacional-, llegando a alcanzar los muchos méritos que se le conocen en diversos campos del saber (PecesBarba Martínez, 1982).

El expediente recoge todo el proceso administrativo en virtud del cual Francisco Giner obtuvo el grado de Bachiller en Filosofía, desde la retribución de un total de cien reales por los derechos de examen hasta la asamblea constituida por el tribunal evaluador: el Catedrático comisionado por el Rector de la Universidad del distrito, el presidente de la Junta Inspectora, y tres Catedráticos de Latín y Castellano, y de Retórica y Poética. Finalmente, el 17 de junio de 1852 don Francisco Giner lograba «por todos los votos» el grado de Bachiller.

Con todo, cualquier intento de llegar al punto de término resulta vano. Lejos de agotarse esta panorámica de la trayectoria inicial de un Francisco Giner discente en una retrospección de carácter rememorativo, el fondo conservado en el Instituto Jorge Juan de Alicante incita a recrear una realidad cuya importancia estriba en los puntales del don Francisco Giner - conocimiento, sentimiento y voluntad — que transita estas páginas como un día lo hiciera por los montes del Guadarrama, allí donde —Machado dixit- «el maestro un día / soñaba un nuevo florecer de España». 


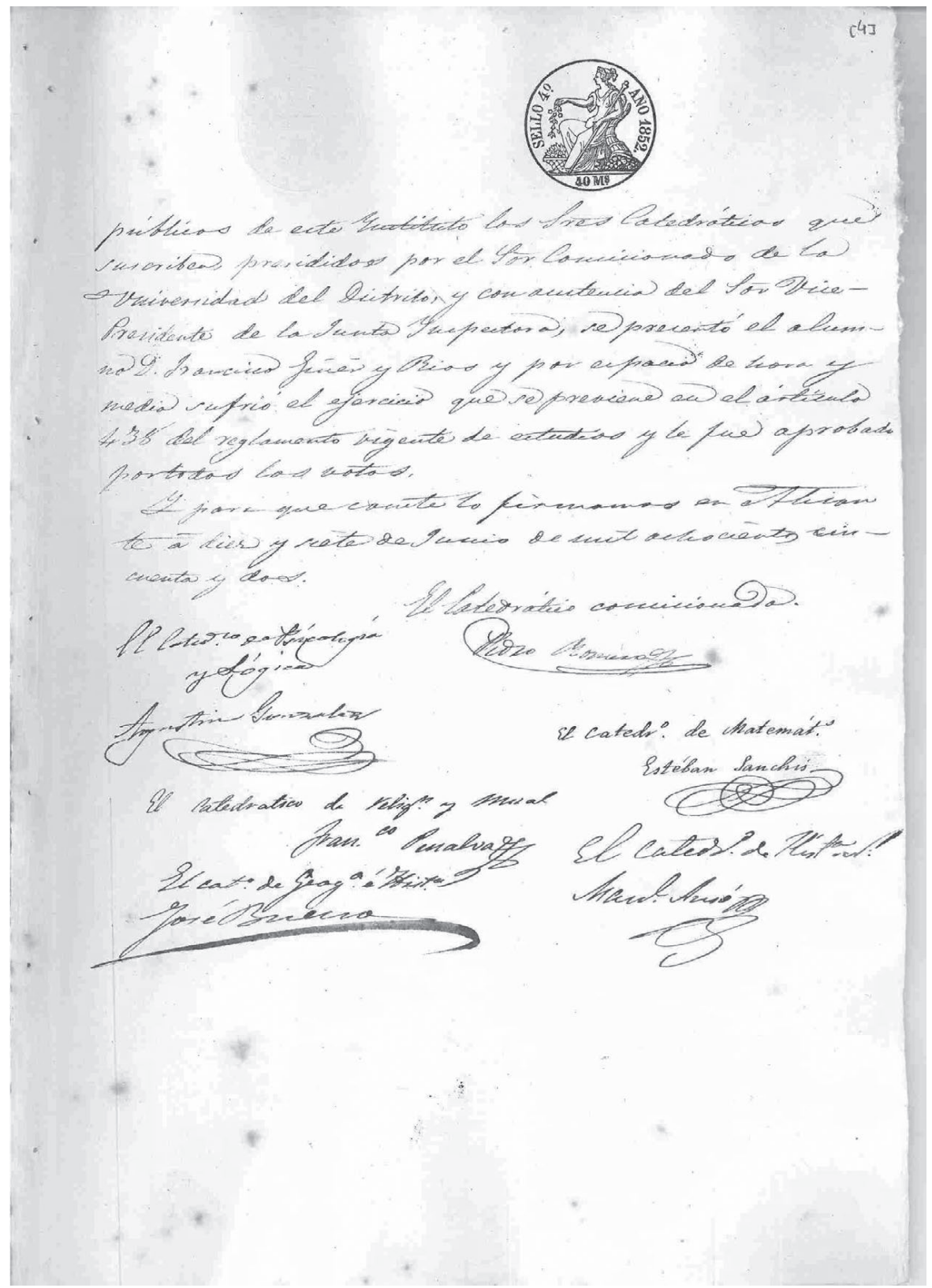

Imagen 7. Evaluación del tribunal a favor de la obtención del grado de Bachiller en Filosofía. 


\section{Bibliografía citada}

Álvarez Lázaro, Pedro F. \& José Manuel VÁzquez-Romero (eds.), Krause, Giner y la Institución Libre de Enseñanza: nuevos estudios, Madrid, Ministerio de Ciencia y Tecnología, 2005.

Cerdán TATO, Enrique, La Gatera [1993], Alicante, Biblioteca Virtual Miguel de Cervantes, 2003; <http://www.cervantesvirtual.com/obra-visor-din/la-gatera1994--0/html/> [consulta: 24 septiembre 2015].

GIL DE ZÁRATE, Antonio, De la instrucción pública en España, I, Madrid, Imprenta del Colegio de Sordo-mudos, 1855.

GINER DE LOS Ríos, Francisco, Ensayos menores sobre educación y enseñanza, 3 vols., en Obras completas, Madrid, Espasa-Calpe, 1927.

- Escritos sobre la universidad española, ed. Teresa Rodríguez de Lecea, Madrid, Espasa-Calpe, 1990.

JAÉN I URBAN, Gaspar (ed.), Guía de arquitectura de la provincia de Alicante, Alicante, Instituto de Cultura Juan Gil-Albert, 1999.

JiMÉNEZ-LANDI MARTíNEZ, Antonio, La Institución Libre de Enseñanza y su ambiente: periodo parauniversitario, II, Madrid, Editorial Complutense, 1996.

Machado, Antonio, Campos de Castilla, ed. Geoffrey Ribbans, Madrid, Cátedra, 1994.

Martínez Blanco, Antonio, La enseñanza de la religión en los centros docentes, Murcia, Universidad de Murcia, 1994.

PeCes-BARba MARTínez, Gregorio, «La enseñanza de la Filosofía del Derecho», Revista de la Facultad de Derecho de la Universidad Complutense, 5 (1982), pp. 99-110.

Puelles, Benítez, Manuel de, Política y educación en la España contemporánea, Madrid, UNED, 2011.

Real Decreto aprobando el Plan General de estudios, redactado por Antonio Gil de Zárate, 1845; <http://www.filosofia.org/mfa/fae845a.htm> [consulta: 24 septiembre 2015].

Ríos Urruti, Fernando de los, El pensamiento vivo de Francisco Giner, Buenos Aires, Losada, 1949.

Ruiz BERRIO, Julio, «El Plan Pidal de 1845: Los institutos públicos, dinamizadores de las capitales de provincia», Participación Educativa, 7 (2008), pp. 28-38.

Tiana Ferrer, Alejandro, Gabriela Ossenbach SAUter \& Florentina SAnZ FERnÁNDEZ, Historia de la educación (Edad Contemporánea), Madrid, UNED, 2012.

VALDÉS, Andrés, «La casa superviviente», Información, 2011; <http://www.diarioinformacion.com/cultura/2011/01/02/casa-superviviente/1080504.html> [consulta: 27 septiembre 2015]. 
Viravens y PASTOR, Rafael, Crónica de la muy ilustre y siempre fiel ciudad de Alicante, Alicante, Imprenta de Carratalá y Gadea, 1876.

Fecha de recepción: 30-4-2015

Fecha de aceptación: 3-10-2015 